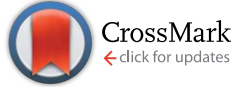

Cite this: RSC Adv., 2017, 7, 13019
Received 17th October 2016 Accepted 21st February 2017

DOI: 10.1039/c6ra25351b

rsc.li/rsc-advances

\section{Dynamical regime of resorcinol based Belousov- Zhabotinsky chemical oscillator in the presence or absence of some hydrophobic antioxidants in aqueous-organic mixed media}

\begin{abstract}
Nadeem Bashir Ganaie*ab and Ghulam Mustafa Peerzada ${ }^{a}$
This study aims to overcome the difficulty of using hydrophobic moieties like antioxidants, hormones, etc. in oscillatory chemical reactions due to existing solubility problems in aqueous acid media. Several new perturbants viz. hydrophobic antioxidants have been found to affect the oscillatory parameters under batch conditions in the resorcinol based Belousov-Zhabotinsky (BZ) oscillating system performed in aqueous-organic mixed media. The $\alpha$-tocopherol, 4,4,4-trifluoro-3-methyl-2-butenoic acid, melatonin and $\beta$-carotene react with radicals either generated from BZ reagents or from the organic solvents and scavenge them. One to one interactions of these additives with resorcinol, bromate or $\mathrm{Mn}(॥)$ ions have been investigated using cyclic voltammetry and potentiometry. These interactions may lead to a better understanding of their mechanism corresponding to their role in the BZ chemical oscillators. A comparative trend of these antioxidants was observed. It is noteworthy to mention here that radical based polymerization has been achieved using a specific solvent system containing monomers of that polymer and an interesting behavior oscillatory parameters was observed during polymer synthesis in situ.
\end{abstract}

\section{Introduction}

Oscillating reactions are complex dynamic systems that involve cyclic or periodic changes in the concentration of some ingredients (whether a reactant, a product or an intermediate) with time. ${ }^{1}$ This type of system has been known since 1910 , when the first model for an oscillating chemical system was developed. ${ }^{2,3}$ Oscillating reactions have so far been analyzed mainly in physico-chemical terms in order to elucidate the complex mechanism involved. Two of the better known oscillating chemical systems are the Belousov-Zhabotinsky (BZ) reaction $^{4-10}$ and the Bray-Liebhafsky reaction..$^{11-13,15}$ From the available knowledge on these reactions, it follows that the system must be far from thermodynamic equilibrium i.e., $\Delta G$ must be large and negative, which entails using a well stirred continuous-flow reactor (CSTR), ${ }^{14,16-18}$ and that one or more autocatalytic or cross-catalytic steps must take place between two steps of the reaction mechanism. ${ }^{19}$ Although some oscillating reactions have been used for analytical purposes, particularly the $\mathrm{Ce}^{4+}$-catalyzed reaction between malonic acid and $\mathrm{KBrO}_{3}$, known as $\mathrm{BZ}$ reaction, ${ }^{20,21}$ analytical determinations based on a closed system including the analyte involve labour-

${ }^{a}$ Department of Chemistry, University of Kashmir, Hazratbal, Srinagar 190 006, J\&K, India. E-mail: nadeemganaie@rediffmail.com; peerzada_gmp@yahoo.co.in

${ }^{b}$ Department of Chemistry, Govt. College for Women, Nawakadal, Srinagar 190002 , $J \& K$, India intensive procedures that entail re-starting the oscillating system before each new determination. This accounts for the little interest aroused so far by this type of reaction for analytical purposes. The recent inception of an open system for application of the analyte pulse perturbation (APP) technique by use of a $\operatorname{CSTR}^{22-28}$ has opened up new avenues for oscillating reactions in routine analyses. As a result, there has been a gradual shift from theoretical to practical interest.

Several subjects were determined by the APP technique, such as riboflavin, ${ }^{29}$ gallic acid, resorcinol, ${ }^{26}$ ascorbic acid, ${ }^{14,30}$ glutamic acid, ${ }^{31}$ glutathione ${ }^{24}$ paracetamol, ${ }^{14,32}$ 1-naphthylamine, ${ }^{33}$ thallium ${ }^{34}$ morphine, ${ }^{35}$ vanillin, ${ }^{14}$ alpha-naphthol ${ }^{36}$ and Alizarin Red S using tetraazamacrocyclic complex of copper, ${ }^{37}$ but all these studies took place in aqueous acid media only.

The catalytic redox couples involved in these $\mathrm{BZ}$ reaction focused on $\mathrm{Ce}^{3+} / \mathrm{Ce}^{4+}, \mathrm{Mn}^{2+} / \mathrm{Mn}^{3+}, \mathrm{Fe}(\text { phen })_{3}{ }^{2+} / \mathrm{Fe}(\text { phen })_{3}{ }^{3+}$ and $\mathrm{Ru}(\mathrm{bpy})_{3}{ }^{2+} / \mathrm{Ru}(\mathrm{bpy})_{3}{ }^{3+}$. Recently, macrocyclic complexes as catalysts were widely investigated. The first publication was of a catalytic macrocyclic complex of $\mathrm{Cu}$ (II) and $\mathrm{Ni}(\mathrm{II})$ reported by Yatsimirskii in $1982 . .^{38}$ Lately, BZ reactions catalyzed by these complexes have attracted much more attention because of their unusual oscillating features, which are reflected in lower activation energies, higher oscillating frequencies ${ }^{39}$ and being vulnerable to external perturbations. By using macrocyclic $\mathrm{Cu}$ (II) or $\mathrm{Ni}(\mathrm{II})$ complexes as catalyst, the oscillating reactions involving lactic acid, ${ }^{40,41}$ malonic acid, ${ }^{42}$ and pyruvic acid $^{43}$ as organic substrate species have been studied. Recently, a new BZ 
<smiles>Cc1c(C)c2c(c(C)c1O)CC[C@@](C)(CCC[C@H](C)CCC[C@H](C)CCCC(C)C)O2</smiles>

a) Structure of $\alpha$-Tocopherol<smiles>CC(CC(=O)O)C(F)(F)F</smiles>

b) Structure of TFMBA<smiles>COc1ccc2[nH]cc(CCNC(C)=O)c2c1</smiles>

c) Structure of Melatonin<smiles>CC1=C(/C=C/C(C)=C/C=C/C(C)=C/C=C/C=C(C)/C=C/C=C(C)/C=C/C2=C(C)CCCC2(C)C)C(C)(C)CCC1</smiles>

d) Structure of $\beta$-Carotene

Scheme 1

oscillating system with a tetraazamacrocyclic copper(II) complex $[\mathrm{CuL}]\left(\mathrm{ClO}_{4}\right)_{2}$ as catalyst and malic acid substrate ${ }^{44}$ have been reported. The ligand, L, in the complex is $5,7,7,12,14,14$ hexamethyl-1,4,8,11-tetraazacyclotetradeca-4,11-diene. Based on this new BZ oscillating system, $\mathrm{Ag}^{+}$(ref. 39) and pyrogallol ${ }^{45}$ were determined by perturbations of analyte on the oscillating system.

However, all these APP determinations involve substrates which were soluble in aqueous acid media and thus restricted the use of hydrophobic species like vitamins, antioxidants or hormones as perturbants in such systems. During this study, we have worked on several organic-aqueous mixed media to evaluate the best one that can be used for deterministic studies in future. Here, four hydrophobic biologically important antioxidants have been used as perturbants, solubilized by these non aqueous mixed media under unstirred batch conditions, as was the case with resorcinol as substrate in our previous works ${ }^{46-48}$ and this has opened a new chapter to carry out the investigations with similar other hydrophobic species in future. The resorcinol has been chosen owing to its sufficient solubility in aqueous acid medium and dynamic behavior over a wide range of concentrations. ${ }^{47}$ Moreover, the presence of two phenolic $\mathrm{OH}$ groups in resorcinol exhibits some similarity with several biomolecules and, therefore, the used of this substrate served in two ways; (i) it can serve as a prototype example in understanding the behaviors possible in biology such as signal transmission and membrane transport in living organisms and (ii) it can help in further establishing the mechanism of aromatic substrates in these complex oscillatory chemical reactions.

The main objective of this work was to solubilize the hydrophobic antioxidants like $\alpha$-tocopherol, 2,2,2-trifluoro-3methyl-2-butenoic acid (TFMBA), melatonin $\{N$-acetyl-5methoxytryptamine or $\quad N$-[2-(5-methoxy-1H-indol-3-yl)ethyl] acetamide $\}$ and $\beta$-carotene, which generally act as radical scavengers in living systems, in acetonitrile (ACN) and 
acrylonitrile/dimethylformamide (AN/DMF) based aqueous organic mixed media. Although various other non-aqueous solvents have been attempted for the study such as THF, dioxane, DMF alone, $n$-hexane and amyl alcohol but all of them undergo either extensive bromination or didn't yield the expressive nonlinear behavior, thus limiting their use as feasible solvents in BZ reaction. The AN/DMF based mixed media, whose ratio has been specifically reached at by hit and trial methods, is of special interest because of observation of in situ radical polymerization and the use of antioxidants in this solvent system caused delay of polymerization reaction due to radical quenching phenomenon (Scheme 1).

\section{Experimental}

\section{Materials}

The reagents used were resorcinol (Aldrich), potassium bromate (Merck), manganese(II) sulfate monohydrate (Aldrich), sulfuric acid (Merck), dimethyl formamide (DMF) (Merck), acetonitrile (ACN) (Merck), acrylonitrile (AN) (Aldrich), $\alpha$-tocopherol (Sigma); 4,4,4-trifluoro-3-methyl-2-butenoic acid (Aldrich), melatonin (Aldrich), $\beta$-carotene (Aldrich). All the reagents used were analytical grade chemicals with high degree of purity and were used without any further purification. The solutions of the desired chemicals were prepared in respective percentages of organic solvents ( $5 \% \mathrm{v} / \mathrm{v}$ for acetonitrile and $5 \% \mathrm{v} / \mathrm{v}$ AN: $4.4 \% \mathrm{v} / \mathrm{v}$ DMF for other solvent system) in $1.4 \mathrm{~mol} \mathrm{~L}^{-1}$ sulfuric acid using double distilled water. In this study the initial concentrations of BZ reagents like resorcinol, bromate and $\mathrm{MnSO}_{4}$ solutions are $0.0225 \mathrm{~mol} \mathrm{~L}^{-1}, 0.1 \mathrm{~mol} \mathrm{~L}^{-1}$ and $0.005 \mathrm{~mol} \mathrm{~L}^{-1}$ respectively (for all those reaction systems where concentrations are not mentioned), which are the optimal concentrations for producing typical time dependant oscillatory regime, i.e. with optimal oscillatory parameters like amplitude, number of oscillations, frequency, etc., which is a pre-requisite for perturbation studies. The oscillations are observed by adding bromate solution to the mixture of resorcinol and $\mathrm{Mn}^{2+}$ ion solution.

\section{Procedure}

Simple potentiometric studies have been performed. The reaction system for consists of two reaction cells, connected through salt bridge (potassium nitrate in agar agar). One cell contains platinum electrode in which bromate, resorcinol and $\mathrm{Mn}$ (II) sulfate solutions are mixed and the other contains calomel electrode as reference in which $2.5 \times 10^{-4} \mathrm{~mol} \mathrm{~L}^{-1}$ solution of potassium chloride is kept. Both these electrodes are then hooked to Orion 4 star, pH ISE Ion Analyzer (Cole Parmer (India) Pvt. Ltd.) in order to monitor change in potential (mV) with time (s) connected to PC via RS232 cable and operated through 21CFR11 software. The desired thermostatic conditions of the reaction system under investigation were maintained using Advantec water bath (TBS451PA, Cole Parmer (India) Pvt. Ltd.) with a precision of $\pm 0.1{ }^{\circ} \mathrm{C}$. The advanced cyclic voltammetry (CV) was performed with a potentiostat (SP150, Biologic France. SAS), using three micro electrodes viz. platinum wire and Glassy Carbon Electrode (GCE, ALS QI058,
GC6 $\times 1.6)$ as counter and working electrodes respectively and saturated calomel as reference electrode (SCE, ALS 002056, RE2B, Japan) in a voltammetry cell (ALS 012669, SVC-3), connected to a PC. All the $\mathrm{CV}$ experiments were performed at room temperature $\left(25 \pm 0.5^{\circ} \mathrm{C}\right)$.

The percentage compositions used for two organic media were: $5 \% \mathrm{v} / \mathrm{v}$ for acetonitrile and $5.6 \% \mathrm{v} / \mathrm{v}$ acrylonitrile: $4.4 \% \mathrm{v} / \mathrm{v}$ DMF (mixed), both in $1.4 \mathrm{~mol} \mathrm{~L}{ }^{-1}$ of $\mathrm{H}_{2} \mathrm{SO}_{4}$. The solutions of all the reagents as well as antioxidants of desired concentrations were prepared in aqueous-organic mixed media. Except bromate solution, all the BZ reagent solutions including that of antioxidants of suitable concentrations were prepared in organicaqueous acid mixed media, to avoid the direct early reaction of the former, as bromate is responsible for bromination of the organic solvent as well. As reported in our previous papers ${ }^{46,47}$ also, for potentiometric studies, the volumes of initial reagents which are mixed in a proper sequence (resorcinol and metal first followed by bromate) are $2 \mathrm{~mL}$ each, wherein, bromate solution is always added last out of the $\mathrm{BZ}$ reagents.

\section{Results and discussion}

Due to the non feasibility of using all the organic solvents as mentioned above, we have chosen only two for their better oscillatory parameters. Acetonitrile based system is having prominent amplitudes for the main BZ system and bromination of organic substrate in presence of acetonitrile is favored ${ }^{49}$ and there may be lesser bromination of antioxidants in presence of this solvent mixture, because the solvent occupies all the sites where bromination can take place. Hence the effect observed is mostly due to quenching of radicals generated in situ by the antioxidants. It is to be noted here that owing to the different chemical structure of antioxidants which may act as

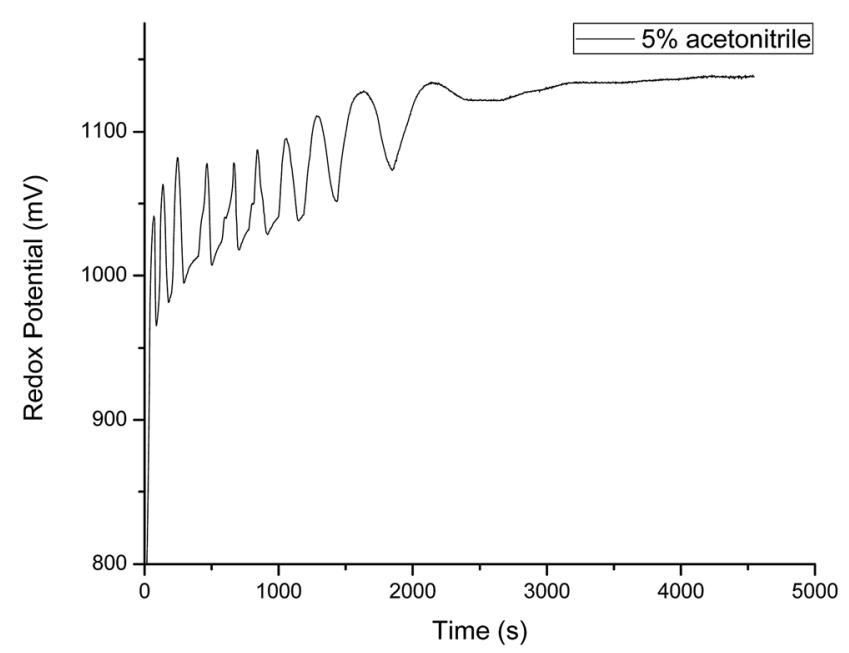

Fig. 1 Typical oscillatory profile of the system containing [resorcinol] $=0.0225 \mathrm{~mol} \mathrm{~L}^{-1},\left[\mathrm{BrO}_{3}^{-}\right]_{0}=0.16 \mathrm{~mol} \mathrm{~L}^{-1},\left[\mathrm{Mn}^{2+}\right]_{0}=0.005 \mathrm{~mol} \mathrm{~L}^{-1}$ in $5 \% \mathrm{v} / \mathrm{v}$ acetonitrile prepared in $1.4 \mathrm{~mol} \mathrm{~L}^{-1}$ of $\left[\mathrm{H}_{2} \mathrm{SO}_{4}\right]_{0}$ at $30{ }^{\circ} \mathrm{C} \mathrm{BrO}_{3}{ }^{-}$ solution is prepared in only aqueous acid and the other reagents in aqueous-organic mixed media. $2 \mathrm{~mL}$ of each of the reagents are mixed in the reaction vessel $(25 \mathrm{~mm} \times 100 \mathrm{~mm})$ with resorcinol and $\mathrm{Mn}^{2+}$ solutions first followed by bromate solution. 
bromination centers upon one to one interaction of bromine and these antioxidants, we have also tried for using them as main substrates in the BZ reaction, but none of them showed any oscillatory regime. However, in all these systems the potential first showed continuous increase and then decreases. This can be due to the quenching of radicals generated in situ by these antioxidants and antioxidants don't take part in autocatalytic reaction steps as per $\mathrm{FKN}^{50}$ and $\mathrm{OKN}^{51}$ mechanisms. The second solvent system chosen was AN/DMF based system, which was specifically chosen in order to confirm the radical generation in situ as well as role of $\mathrm{BZ}$ reagents and intermediates in the polymer matrix. This study may help in understanding radical control because of generation of polymers in situ.

\section{Acetonitrile based mixed media}

Fig. 1 gives us the typical oscillatory profile of the resorcinol based BZ system in acetonitrile based mixed medium. Large amplitude oscillations was observed for $0.16 \mathrm{~mol} \mathrm{~L}^{-1}\left[\mathrm{BrO}_{3}{ }^{-}\right]$ with decrease in life time than the already known oscillations from aqueous acid medium, ${ }^{\mathbf{4 7}}$ hence, used as typical oscillatory profile for this medium.

\section{Antioxidants in acetonitrile based media}

Addition of antioxidants to the above mentioned system normally quenches the oscillations, but the extent of quenching under given conditions varies with the nature of the hydrophobic antioxidant used. The quenching for these antioxidants under given conditions is shown by the following trend:

$$
\alpha \text {-tocopherol }<\text { TFMBA }<\text { melatonin }<\beta \text {-carotene }
$$

Quite contrary to the effect of antioxidants, $0.005 \mathrm{~mol} \mathrm{~L}^{-1}$ concentration of $\alpha$-tocopherol had shown increased number of oscillations after a gap of $2000 \mathrm{~s}$, which is due to its complete consumption in situ and due to the formation of para-quinonoid species, which decreases its radical quenching behavior. Bohmdorfer, et al. found that in case of $\alpha$-tocopherol, halogenating effect is minor and the major pathway is the oxidative action resulting in the para-quinone. ${ }^{52}$ Hence, the bromination is mainly observed by the resorcinol instead of $\alpha$-tocopherol. Further, it is observed that increasing the concentration of TFMBA up to $0.005 \mathrm{~mol} \mathrm{~L}^{-1}$ and for $\beta$-carotene up to $0.0005 \mathrm{~mol}$ $\mathrm{L}^{-1}$ completely quenches the oscillations. TFMBA is having a $\mathrm{C}=\mathrm{C}$ in the molecule, but owing to its proximity with most electronegative three fluorine atoms it does not favor the attack of bromonium ion for bromination. Therefore, bromine generated in situ will be mostly used by in FKN mechanism. Fig. 2 gives a comparative data of different antioxidants as perturbants/radical scavengers. Out of these $\beta$-carotene has been found to be strong quencher followed by melatonin for

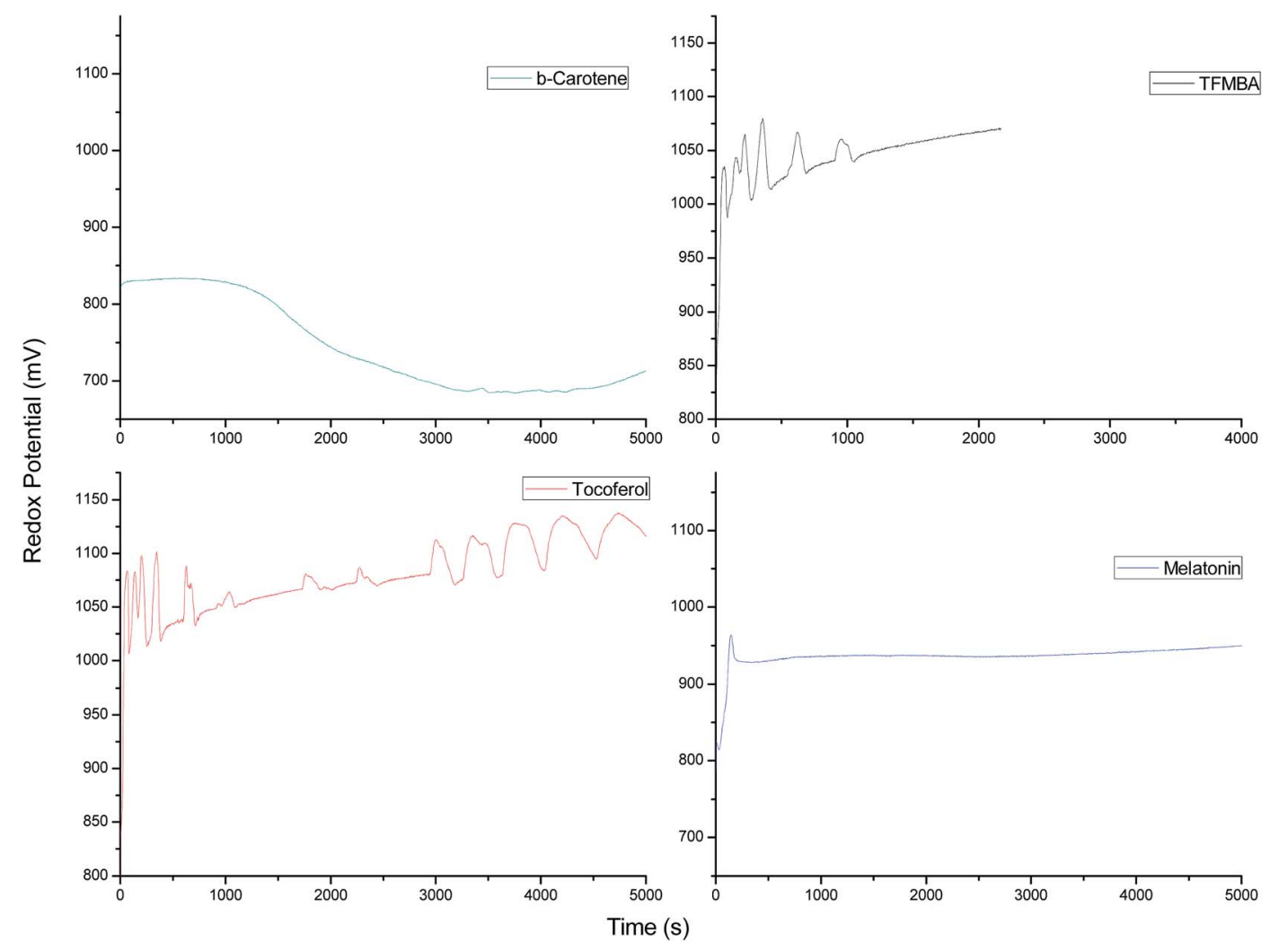

Fig. 2 Potential (mV) versus time (s) plots of the oscillations of resorcinol- $\mathrm{BrO}_{3}{ }^{-}-\mathrm{Mn}^{2+}-\mathrm{H}_{2} \mathrm{SO}_{4}$ system in $5 \%$ v/v acetonitrile organic - aqueous mixed media after perturbation by $0.5 \mathrm{~mL}$ of different antioxidants, added just after the addition of $\mathrm{BrO}_{3}{ }^{-}$solution. The added concentration for $\beta$-carotene and $\alpha$-tocopherol is $0.005 \mathrm{~mol} \mathrm{~L}^{-1}$ and for 4,4,4-trifluoro-3-methyl-2-butenoic acid (TFBMA) and melatonin $=0.0025 \mathrm{~mol} \mathrm{~L}^{-1}$. The concentration of BZ mixture is given in Fig. 1. 


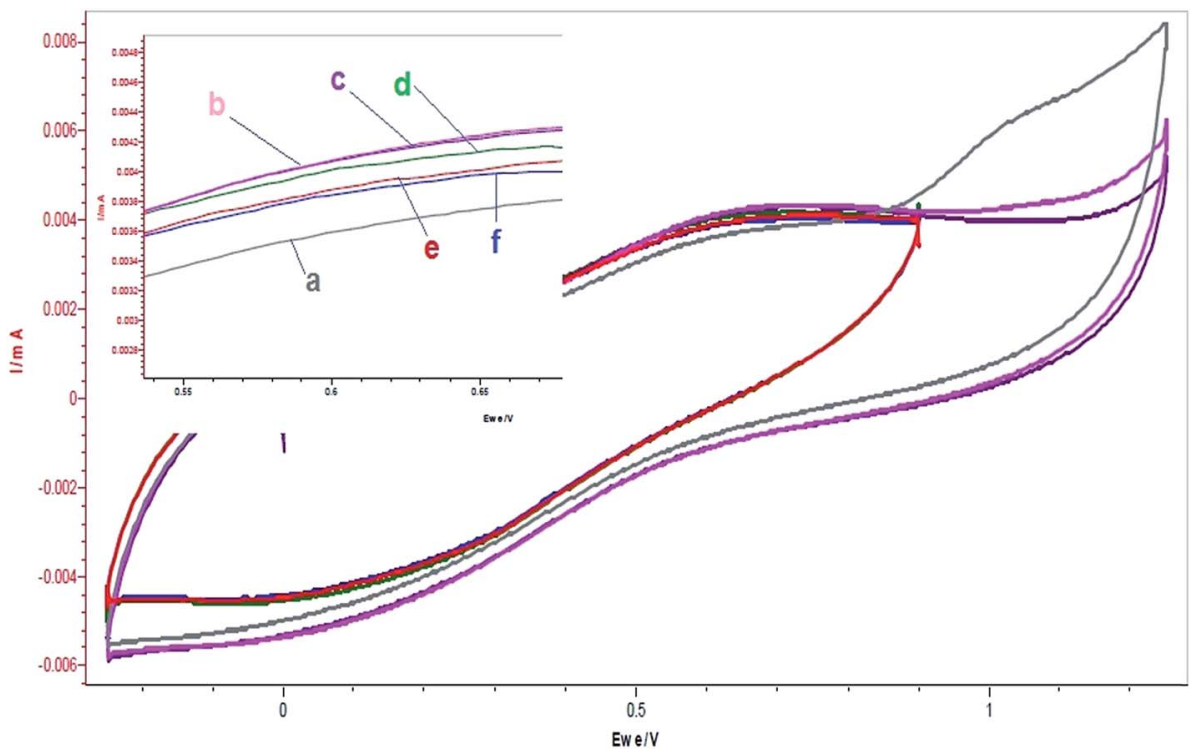

Fig. 3 Cyclic voltammograms of the reactions of resorcinol $\left(0.0225 \mathrm{~mol} \mathrm{~L}^{-1}\right)+\left[\mathrm{BrO}_{3}{ }^{-}\right]_{0}\left(=0.1 \mathrm{~mol} \mathrm{~L}^{-1}\right)$ at different times and different volume additions of $[\beta \text {-carotene }]_{0}=0.005 \mathrm{~mol} \mathrm{~L}^{-1}$ : (a) resorcinol $=5 \mathrm{~mL}$, (b) resorcinol $+3 \mathrm{~mL} \mathrm{BrO}_{3}^{-}$(c) resorcinol $+3 \mathrm{~mL} \mathrm{BrO}_{3}^{-}$after $3 \mathrm{~min}$, (d) resorcinol $+3 \mathrm{~mL} \mathrm{BrO}_{3}{ }^{-}+2 \mathrm{~mL} \beta$-carotene, (e) resorcinol $+3 \mathrm{~mL} \mathrm{BrO}_{3}{ }^{-}+2 \mathrm{~mL} \beta$-carotene after $3 \mathrm{~min}$, (f) resorcinol $+3 \mathrm{~mL} \mathrm{BrO}{ }^{-}+4 \mathrm{~mL} \beta$ carotene. (Resorcinol and $\beta$-carotene solutions are prepared in $5 \% \mathrm{v} / \mathrm{v}$ acetonitrile in $\left[\mathrm{H}_{2} \mathrm{SO}_{4}\right]_{0}=1.4 \mathrm{~mol} \mathrm{~L}^{-1} \mathrm{and} \mathrm{BrO}_{3}^{-}$in $1.4 \mathrm{~mol} \mathrm{~L}^{-1}\left[\mathrm{H}_{2} \mathrm{SO}_{4}\right]$.) Scan rate $=200 \mathrm{mV} \mathrm{s}^{-1}$.

oscillations, whereas $\alpha$-tocopherol shows oscillations for a longer life time followed by TFMBA which also show some oscillations under given conditions. There is marked increase in number and amplitude of oscillations in case of $\alpha$-tocopherol, which may be due to its complete consumption in quenching radicals and reducing metal ion in the autocatalytic process of oscillatory reactions. ${ }^{47}$ When whole of the antioxidant is used up, the intermediates regenerate and oscillations with larger time periods re-emerge. But it was observed that increasing the concentration from 0.005 to $0.01 \mathrm{~mol} \mathrm{~L}^{-1}$ for $\alpha$-tocopherol and up to $0.001 \mathrm{~mol} \mathrm{~L}^{-1}$ for melatonin, completely quenched the oscillations under given set of conditions. Further, the addition of melatonin and $\beta$-carotene initially decreased the overall potential of the system, which is due to the reactions of

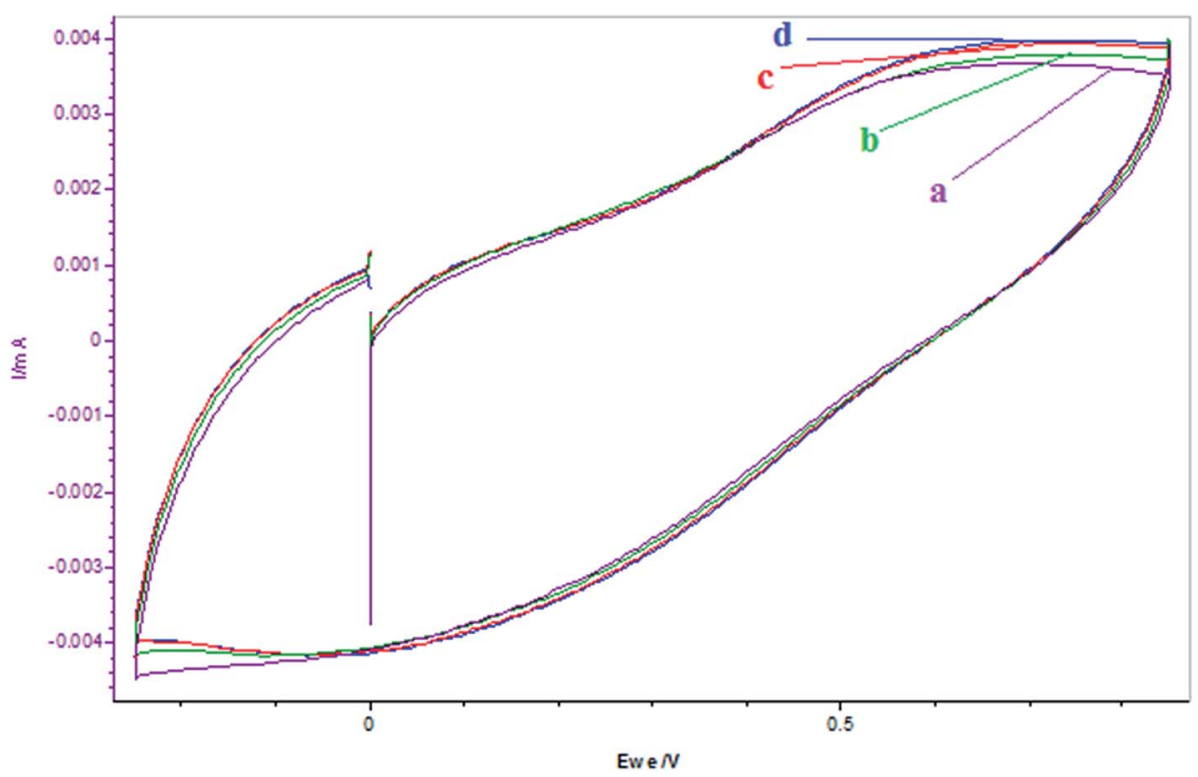

Fig. 4 Cyclic voltammograms of the reactions of $\mathrm{MnSO}_{4}\left(0.005 \mathrm{~mol} \mathrm{~L}^{-1}\right)+[\beta \text {-carotene }]_{0}=0.005$ mol L $\mathrm{L}^{-1}$ at different times and addition of [resorcinol] ${ }_{0}=0.0225 \mathrm{~mol} \mathrm{~L}^{-1}$ : (a) $\mathrm{MnSO}_{4}=5 \mathrm{~mL}$, (b) $\mathrm{MnSO}_{4}+2 \mathrm{~mL} \beta$-carotene (c) $\mathrm{MnSO}_{4}+2 \mathrm{~mL} \beta$-carotene after $5 \mathrm{~min}$, (d) $\mathrm{MnSO}_{4}+2 \mathrm{~mL} \beta$ carotene $+3 \mathrm{~mL}$ resorcinol. $\mathrm{MnSO}_{4}, \beta$-carotene and resorcinol solutions are prepared in $5 \% \mathrm{v} / \mathrm{v}$ acetonitrile in $\left[\mathrm{H}_{2} \mathrm{SO}_{4}\right]_{0}=1.4 \mathrm{~mol} \mathrm{~L}^{-1}$. Scan rate $=$ $200 \mathrm{mV} \mathrm{s}^{-1}$. 


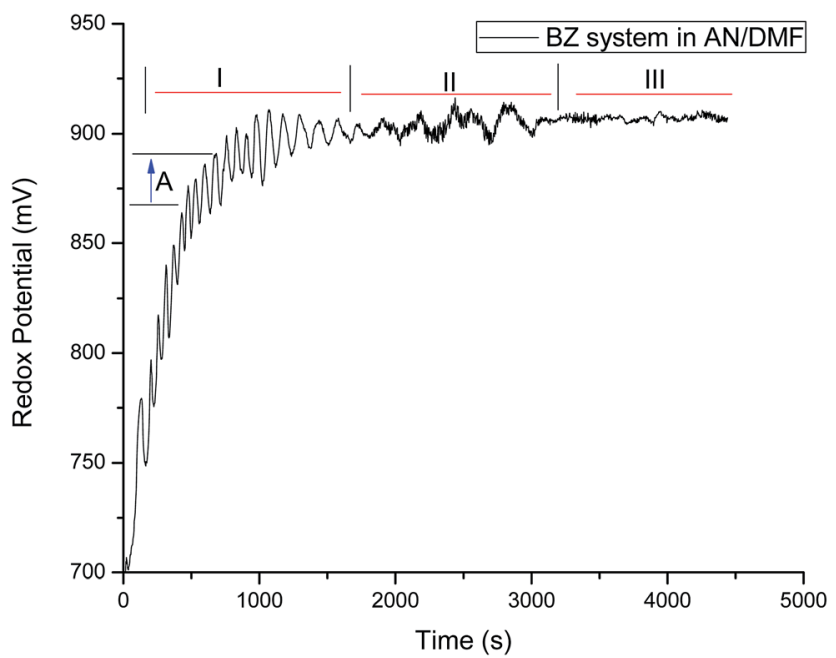

Fig. 5 Typical oscillatory profile of the system containing $2 \mathrm{~mL}$ each of [resorcinol] $]_{0}=0.0225 \mathrm{~mol} \mathrm{~L}-1,\left[\mathrm{BrO}_{3}^{-}\right]_{0}=0.1 \mathrm{~mol} \mathrm{~L}^{-1},\left[\mathrm{Mn}^{2+}\right]_{0}=$ $0.005 \mathrm{~mol} \mathrm{~L}^{-1}$ in $5 \% \mathrm{v} / \mathrm{v}$ AN: $4.4 \% \mathrm{v} / \mathrm{v}$ DMF prepared in $1.4 \mathrm{~mol} \mathrm{~L}^{-1}$ of $\left[\mathrm{H}_{2} \mathrm{SO}_{4}\right]_{0}$ at $30{ }^{\circ} \mathrm{C}$. $\mathrm{BrO}_{3}{ }^{-}$is prepared in aqueous acid medium and the other reagents in aqueous-organic mixed media.

oxybromine species $\left[\mathrm{Br}^{-} / \mathrm{HOBr}, \mathrm{HBrO}_{2} / \mathrm{Br}_{2}\right.$ couples $]$ generated in situ with the antioxidants and increased generation of $\left[\mathrm{Mn}^{3+}\right]$ ion with these, thereby decreasing the $\left[\mathrm{Mn}^{2+}\right] /\left[\mathrm{Mn}^{3+}\right]$ couple. ${ }^{3}$
Melatonin is used due to its role in controlling circadian rhythms and various other biological activities such as inhibition of Alzheimer $\beta$-fibrillogenesis, anti-aging properties relating to radical scavenging activities, etc. and $\beta$-carotene is the dietary source of vitamin A and has antioxidant properties that can help neutralize free radicals like reactive oxygen molecules potentially damaging lipids in cell membranes and genetic material, which may lead to the development of cardiovascular disease and cancer.

The mechanism of resorcinol based $\mathrm{Mn}^{2+}$ catalyzed $\mathrm{BZ}$ system can be understood by the following steps (1) to (12). Here, $\operatorname{HAr}(\mathrm{OH})_{2}$ is an aromatic compound (like resorcinol) containing at least two phenolic groups, $\operatorname{HAr}(\mathrm{OH}) \mathrm{O}^{\cdot}$ is the radical obtained by hydrogen atom abstraction, $\mathrm{HArO}_{2}$ is the related quinone, $\operatorname{BrAr}(\mathrm{OH})_{2}$ is the brominated derivative, and $\mathrm{Ar}_{2}(\mathrm{OH})_{4}$ is the coupling product.

$$
\begin{gathered}
\mathrm{BrO}_{3}^{-}+\mathrm{Br}^{-}+2 \mathrm{H}^{+} \leftrightarrow \mathrm{HBrO}_{2}+\mathrm{HOBr} \\
\mathrm{HBrO}_{2}+\mathrm{Br}^{-}+\mathrm{H}^{+} \rightarrow 2 \mathrm{HOBr} \\
\mathrm{BrO}_{3}^{-}+\mathrm{HBrO}_{2}+\mathrm{H}^{+} \leftrightarrow 2 \mathrm{BrO}_{2}+\mathrm{H}_{2} \mathrm{O} \\
\mathrm{BrO}_{2}+\mathrm{HAr}(\mathrm{OH})_{2} \rightarrow \mathrm{HBrO}_{2}+\mathrm{HAr}(\mathrm{OH}) \mathrm{O}^{-}
\end{gathered}
$$

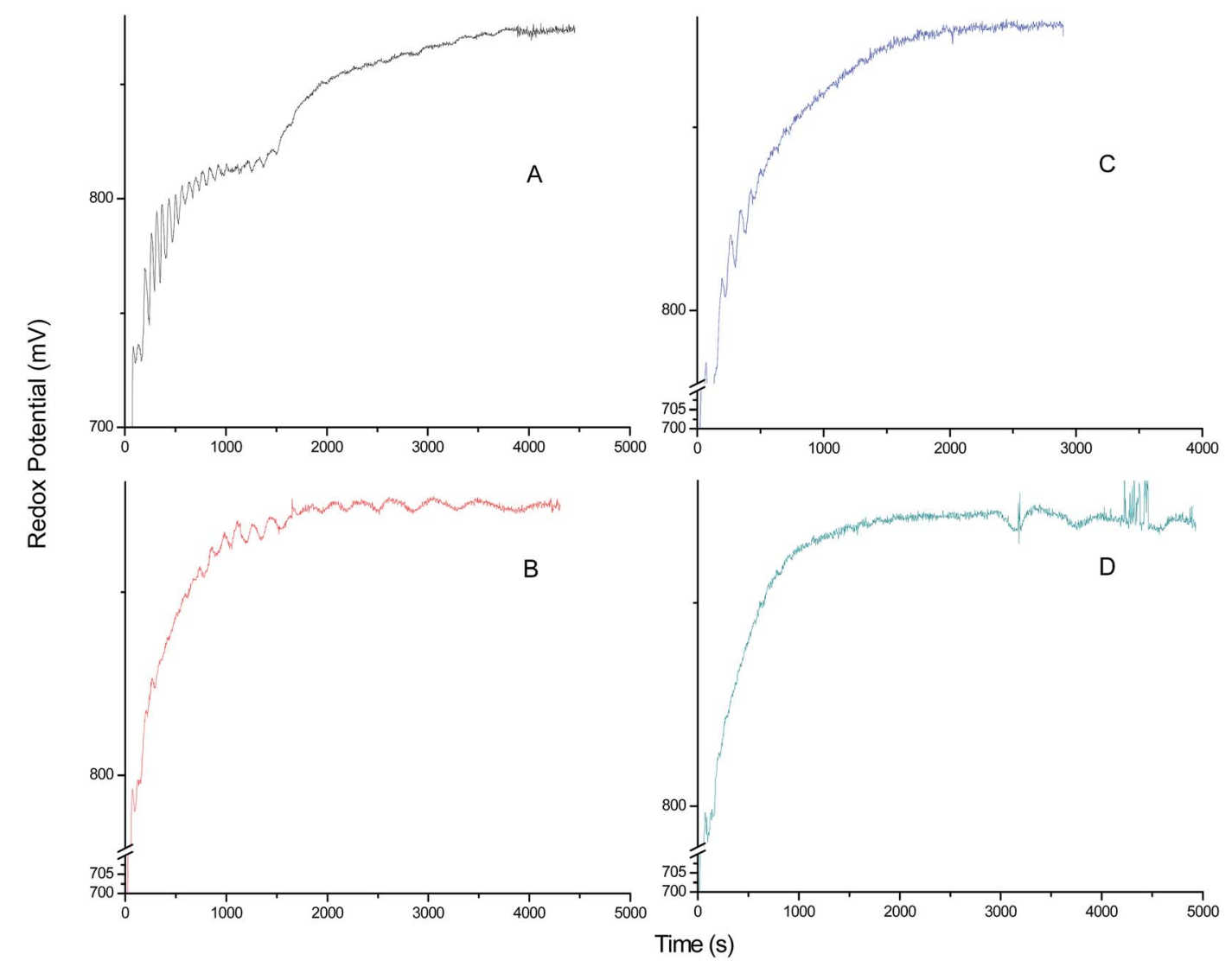

Fig. 6 Potential (mV) versus time (s) plots of the oscillations of resorcinol- $\mathrm{BrO}_{3}{ }^{-}-\mathrm{Mn}^{2+}-\mathrm{H}_{2} \mathrm{SO}_{4} \mathrm{BZ}$ system in $5.6 \% \mathrm{AN}$ : $4.4 \%$ DMF in 1.4 mol $\mathrm{L}^{-1}$ $\mathrm{H}_{2} \mathrm{SO}_{4}$ organic-aqueous acid mixed media, after perturbation by $0.5 \mathrm{~mL}$ of different concentrations of melatonin, added just after the addition of $\mathrm{BrO}_{3}^{-}$solution. The added concentration for melatonin: (A) $0.004 \mathrm{~mol} \mathrm{~L}-1$, (B) $0.006 \mathrm{~mol} \mathrm{~L}^{-1}$, (C) $0.008 \mathrm{~mol} \mathrm{~L}^{-1}$, (D) $0.01 \mathrm{~mol} \mathrm{~L}^{-1}$. The concentrations and volumes of BZ reagents are given in Fig. 5. 


$$
\begin{aligned}
& 2 \mathrm{HBrO}_{2} \rightarrow \mathrm{BrO}_{3}^{-}+\mathrm{HOBr}+\mathrm{H}^{+} \\
& \mathrm{HOBr}+\mathrm{HAr}(\mathrm{OH}) \mathrm{O}^{\bullet} \leftrightarrow \mathrm{Br}^{\bullet}+\mathrm{HArO}_{2}+\mathrm{H}_{2} \mathrm{O} \\
& \mathrm{Br}^{\bullet}+\mathrm{HAr}(\mathrm{OH}) \mathrm{O}^{\bullet} \rightarrow \mathrm{Br}^{-}+\mathrm{HArO}_{2}+\mathrm{H}^{+} \\
& \mathrm{HOBr}+\mathrm{Br}^{-}+\mathrm{H}^{+} \leftrightarrow \mathrm{Br}_{2}+\mathrm{H}_{2} \mathrm{O} \\
& \mathrm{Br}_{2}+\mathrm{HAr}(\mathrm{OH})_{2} \rightarrow \operatorname{BrAr}(\mathrm{OH})_{2}+\mathrm{Br}^{-}+\mathrm{H}^{+} \\
& \mathrm{HOBr}+\mathrm{HAr}(\mathrm{OH})_{2} \rightarrow \mathrm{BrAr}(\mathrm{OH})_{2}+\mathrm{H}_{2} \mathrm{O} \\
& 2\left(\mathrm{BrO}_{3}{ }^{-}+\mathrm{HBrO}_{2}+2 \mathrm{M}_{\mathrm{RED}}+3 \mathrm{H}^{+} \leftrightarrow\right. \\
& \left.2 \mathrm{HBrO}_{2}+2 \mathrm{M}_{\mathrm{OX}}+\mathrm{H}_{2} \mathrm{O}\right) \\
& \mathrm{BrO}_{3}{ }^{-}+4 \mathrm{M}_{\mathrm{RED}}+\mathrm{HAr}(\mathrm{OH})_{2}+5 \mathrm{H}^{+} \rightarrow \\
& \operatorname{BrAr}(\mathrm{OH})_{2}+4 \mathrm{M}_{\mathrm{OX}}+3 \mathrm{H}_{2} \mathrm{O}
\end{aligned}
$$

Fig. 3 showed the interactions of $\beta$-carotene with resorcinol and $\mathrm{BrO}_{3}{ }^{-}$after different time intervals. The cyclic voltammograms for only resorcinol in acetonitrile based mixed medium showed two anodic peaks $(3.75 \mu \mathrm{A}, 6.33 \mu \mathrm{A})$, which are due to oxidation of both the hydroxyl groups on resorcinol. With the addition of $\mathrm{BrO}_{3}{ }^{-}$, there is increase in oxidation peak of one corresponding to main anodic peak of resorcinol based system $(4.31 \mu \mathrm{A})$ and a sharp decrease in the other oxidation peak (4.34 $\mu \mathrm{A})$ or in other words the other peak of other $\mathrm{OH}$ disappears. After certain intervals of time, there is continued decrease in oxidation of the $1^{\text {st }}$ peak corresponding to [resorcinol], which decreased further with the addition of $\beta$-carotene (Fig. $3 \mathrm{c}$ and d). This is due to the partial enhanced stability of the oxidized substrate in this polar medium, which gets decreased by the subsequent bromination of the mixed organic polar medium i.e. acetonitrile, thereby making it less polar and hence favoring oxidation of only one hydroxyl group. With the addition of $\beta$ carotene and after certain intervals of time, there is usual decrease in oxidation of substrate with small generation of

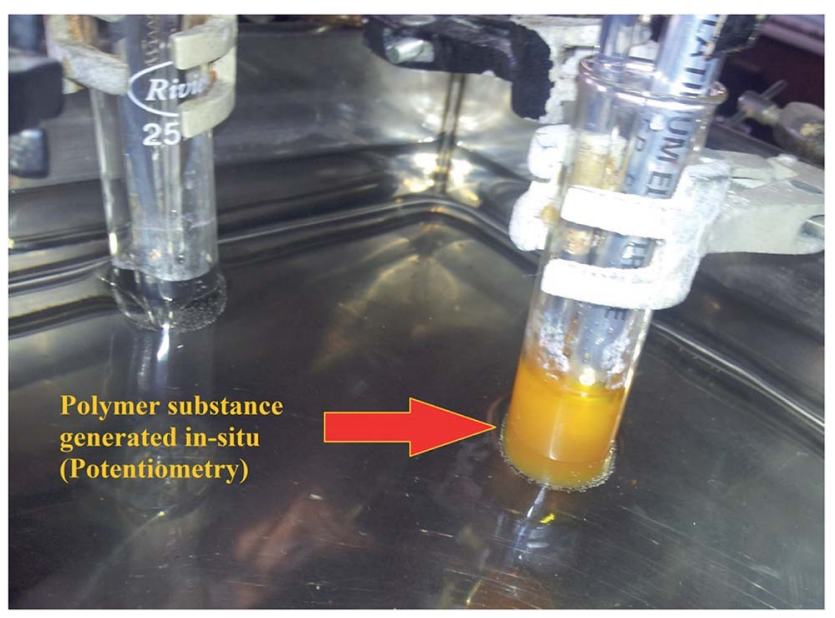

Fig. 7 Polymeric substance generated in situ for the system containing [resorcinol $]_{0}=0.0225 \mathrm{~mol} \mathrm{~L}^{-1},\left[\mathrm{BrO}_{3}{ }^{-}\right]_{0}=0.1 \mathrm{~mol} \mathrm{~L}^{-1},\left[\mathrm{Mn}^{2+}\right]_{0}$ $=0.005 \mathrm{~mol} \mathrm{~L}^{-1}$ in $5 \% \mathrm{v} / \mathrm{v} \mathrm{AN}: 4.4 \% \mathrm{v} / \mathrm{v}$ DMF prepared in $1.4 \mathrm{~mol} \mathrm{~L}^{-1}$ $\left[\mathrm{H}_{2} \mathrm{SO}_{4}\right]_{0}$ at $30{ }^{\circ} \mathrm{C}$. oxybromine species because of radical quenching activity thereby, decreasing the oxidation peak further.

Fig. 4 depicted the $\mathrm{CV}$ for the interactions of $\beta$-carotene with $\mathrm{Mn}^{2+}$ at different times and volume additions of the $\beta$-carotene and resorcinol. It is observed that rate of oxidation increases with time after addition of $\beta$-carotene, whereas addition of resorcinol to this mixture produced marginal increase in oxidation peak current. This is due to the reduction of $\mathrm{Mn}^{3+}$ by the $\beta$-carotene initially, but after some time when whole of the [antioxidant] is consumed. Oxidation peak increases due to formation of $\mathrm{Mn}^{3+}$ species, which have feeble interactions with the resorcinol and the organic solvent as compared to $\mathrm{Mn}^{2+}$ ion. ${ }^{48}$

\section{Interaction of antioxidants in acrylonitrile/DMF based aqueous acid mixed media}

As from our observations regarding the confirmation of polymer species generated in situ for the AN/DMF based mixed medium, it was a good initiative to introduce the antioxidants to this system. The antioxidants are having strong radical scavenging capacity and thus could affect the rate of radical polymerization $v i s-\grave{a}-v i s$ quenching of the radical intermediates generated for BZ system. For this study, all the four antioxidants were used, whereas the thorough studies were carried out for melatonin and $\alpha$-tocopherol with other BZ reagents. Fig. 5 depicts the typical oscillatory profile of resorcinol based system in AN/DMF based mixed medium. For this system, the induction period is $130 \mathrm{~s}$ followed by average time period of about $60 \mathrm{~s}$ (region I), which showed a continuous increase with time. The amplitude decreased steadily up to $1790 \mathrm{~s}$ followed by an increase with increase in time period as well (region II). The peculiarity of this system is that it showed prolonged minimal amplitude oscillations $(5 \mathrm{mV})$ at later stages of the reaction (region III).

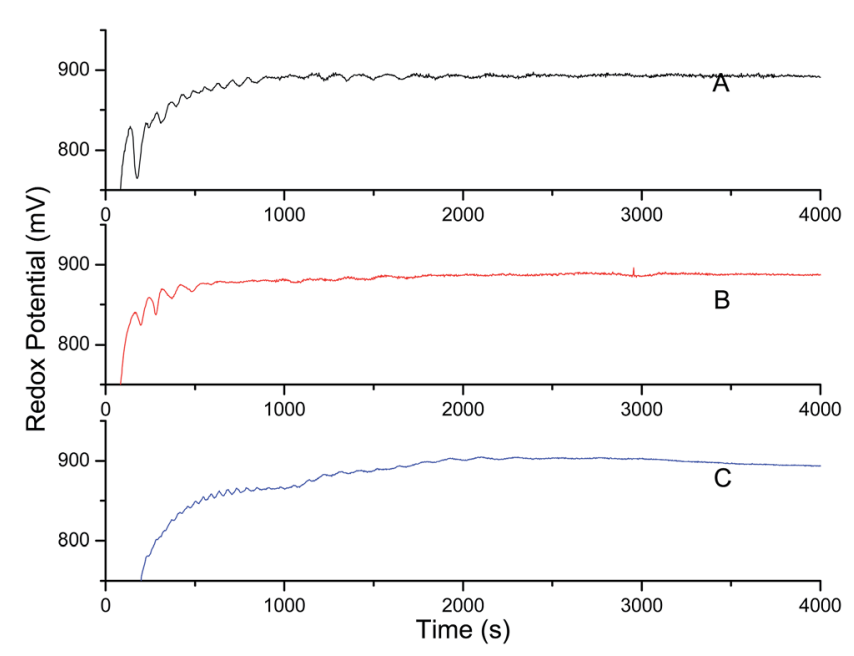

Fig. 8 Potential $(\mathrm{mV})$ versus time (s) plots of resorcinol- $\mathrm{BrO}_{3}{ }^{-}$ $\mathrm{Mn}^{2+}-\mathrm{H}_{2} \mathrm{SO}_{4}$ BZ system in 5.6\% AN: $4.4 \%$ DMF of $1.4 \mathrm{~mol} \mathrm{~L}{ }^{-1} \mathrm{H}_{2} \mathrm{SO}_{4}$ organic aqueous acid mixed media after perturbation by $0.5 \mathrm{~mL}$ of different concentrations of $\alpha$-tocopherol, added just after the addition of $\mathrm{BrO}_{3}{ }^{-}$solution. The added concentration for $\alpha$-tocopherol: (A) $0.0002 \mathrm{~mol} \mathrm{~L}^{-1}$, (B) $0.0004 \mathrm{~mol} \mathrm{~L}^{-1}$, (C) $0.001 \mathrm{~mol} \mathrm{~L}^{-1}$. The concentration and volumes of BZ reagents are given in Fig. 5 . 


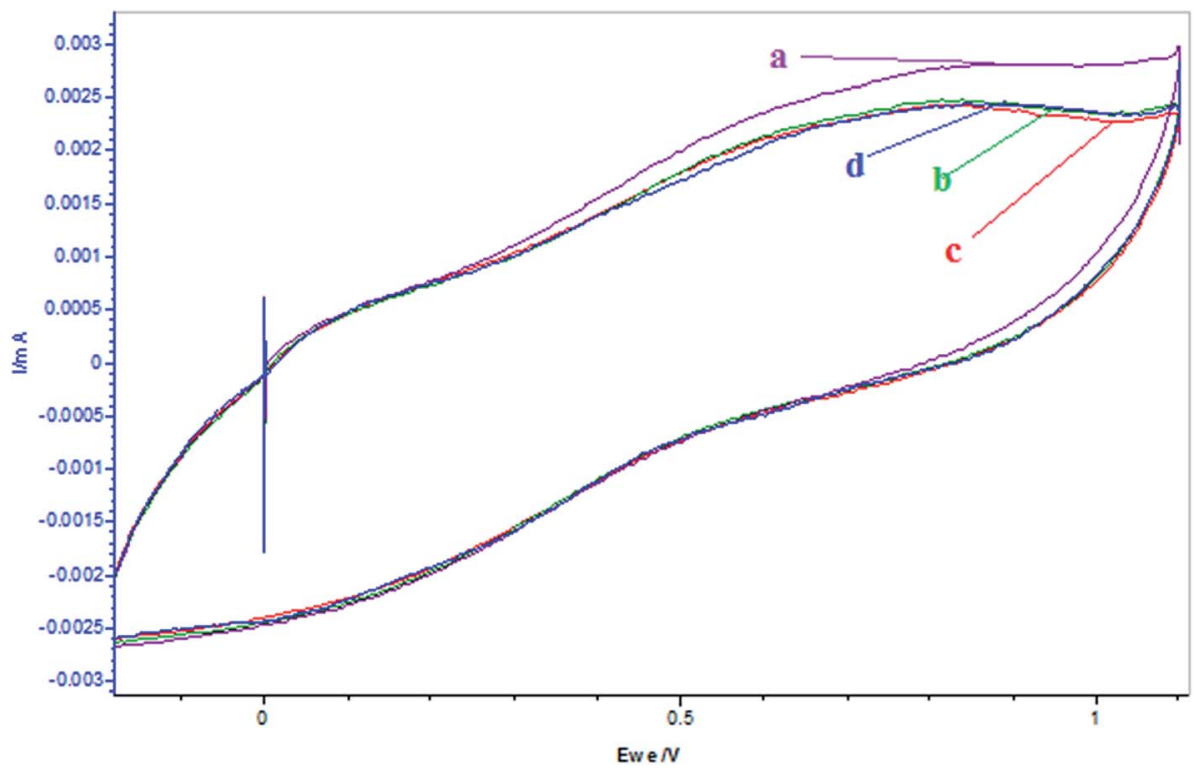

Fig. 9 Cyclic voltammograms of the reactions of $\mathrm{MnSO}_{4}\left(0.005 \mathrm{~mol} \mathrm{~L}^{-1}\right)+[\alpha \text {-tocopherol }]_{0}=0.001$ mol L $\mathrm{L}^{-1}$ at different times after addition of $\alpha$ tocopherol: (a) $\mathrm{MnSO}_{4}$ only $=5 \mathrm{~mL}$, (b) $0 \mathrm{~min}$ (c) $3 \mathrm{~min}$, (d) $15 \mathrm{~min}$. $\mathrm{MnSO}_{4}$, and $\alpha$-tocopherol solutions are prepared in 5.6\% AN: 4.4\% DMF in $1.4 \mathrm{~mol} \mathrm{~L}^{-1} \mathrm{H}_{2} \mathrm{SO}_{4}$ aqueous acid mixed media. Scan rate $=100 \mathrm{mV} \mathrm{s}^{-1}$.)

\section{Melatonin in acrylonitrile/DMF}

The effect of additions of different concentrations of melatonin on the oscillatory behavior of resorcinol based system in this media is depicted from potential-time plots shown in Fig. 6. It is observed that with increase in concentration of melatonin at the start of reaction, there is decrease in number as well as amplitude of large amplitude oscillations. However, there is increase in time period of small amplitude oscillations. This system showed strong quenching for concentrations $\geq 0.01 \mathrm{~mol}$ $\mathrm{L}^{-1}$ of melatonin. This can be due to the radical scavenging activity of melatonin, as was observed from the decreased rate of formation of polymer (yellowish due to bromoresorcinol, actually white precipitate) as depicted in Fig. 7. The polymer material was confirmed using IR and have been synthesized in situ. These polymers were found to be Nearly Ultra High Molecular Weight (NUHMW) polymers with molecular weights

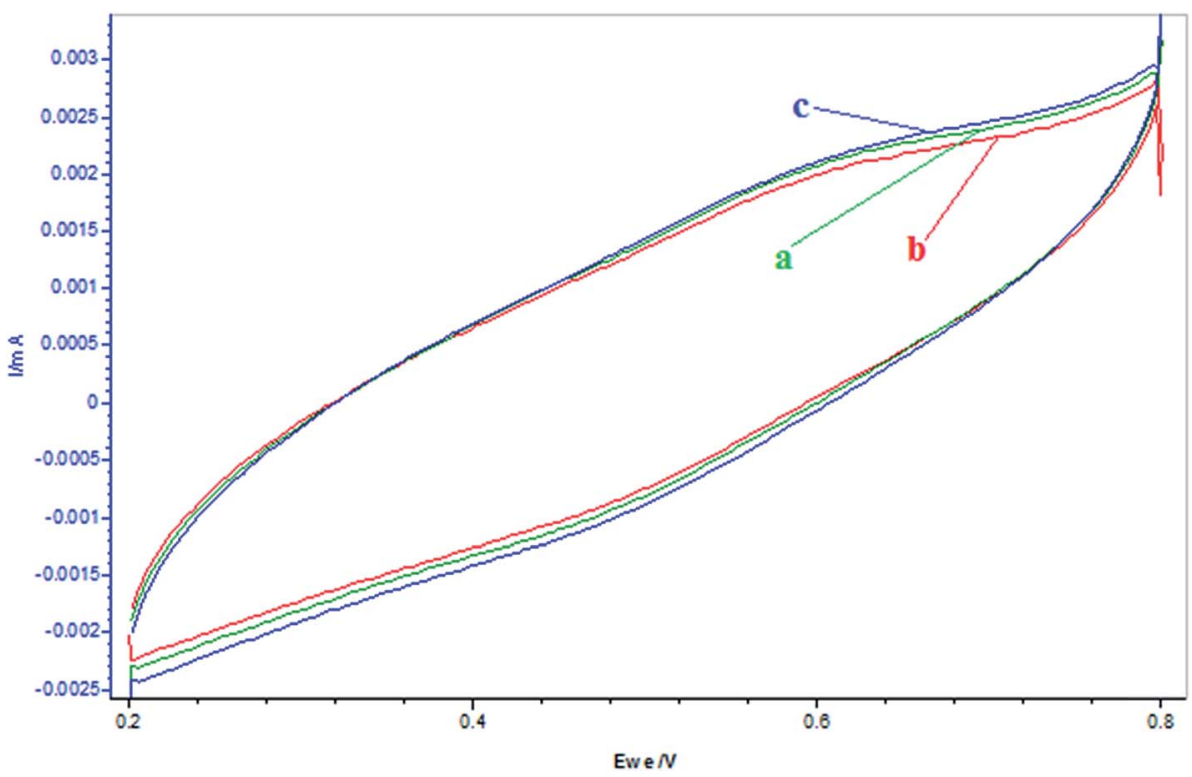

Fig. 10 Cyclic voltammograms of the reactions pertaining to resorcinol $\left(0.0225 \mathrm{~mol} \mathrm{~L}^{-1}\right)+[\alpha \text {-tocopherol }]_{0}=0.003 \mathrm{~mol} \mathrm{~L}{ }^{-1}$ at different times and addition of $\left[\mathrm{BrO}_{3}^{-}\right]_{0}=0.1 \mathrm{~mol} \mathrm{~L}{ }^{-1}$ : (a) resorcinol $=5 \mathrm{~mL}$, (b) resorcinol $+\alpha$-tocopherol after $2 \mathrm{~min}$ (c) resorcinol $+\alpha$-tocopherol $+\mathrm{BrO}_{3}^{-}$. ( $\alpha$ Tocopherol and resorcinol solutions are prepared in 5.6\% AN: $4.4 \%$ DMF in $1.4 \mathrm{~mol} \mathrm{~L}^{-1} \mathrm{H}_{2} \mathrm{SO}_{4}$ and $\mathrm{BrO}_{3}^{-}$is prepared in $1.4 \mathrm{~mol} \mathrm{~L}^{-1} \mathrm{H}_{2} \mathrm{SO}_{4}$ only.) Scan rate $=200 \mathrm{mV} \mathrm{s}^{-1}$. 


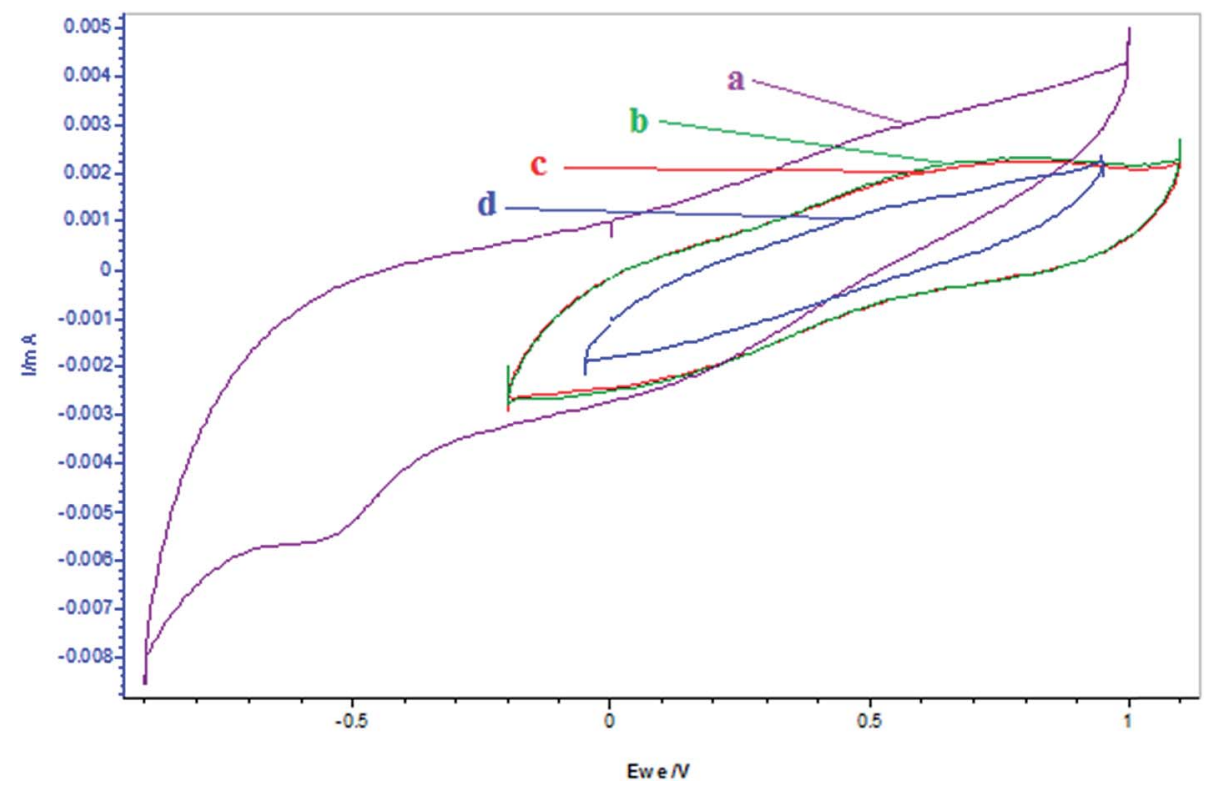

Fig. 11 Cyclic voltammograms of the reactions of $\mathrm{MnSO}_{4}\left(0.005 \mathrm{~mol} \mathrm{~L}^{-1}\right)+\alpha$-tocopherol at different times and additions of $\left[\mathrm{BrO}_{3}{ }^{-}\right]=0.1 \mathrm{~mol}$ $\mathrm{L}^{-1}$ and $\alpha$-tocopherol: (a) $\mathrm{MnSO}_{4}=5 \mathrm{~mL}$, (b) $\mathrm{MnSO}_{4}+\alpha$-tocopherol $=0.001 \mathrm{~mol} \mathrm{~L}^{-1}$, (c) $\mathrm{MnSO}_{4}+\alpha$-tocopherol $=0.002 \mathrm{~mol} \mathrm{~L}^{-1}$ after $25 \mathrm{~min}$, (d) $\mathrm{MnSO}_{4}+\alpha$-tocopherol $=0.002 \mathrm{~mol} \mathrm{~L}^{-1}+2 \mathrm{~mL} \mathrm{BrO}_{3}^{-}$. ( $\alpha$-Tocopherol and $\mathrm{MnSO}_{4}$ solutions are prepared in $5.6 \% \mathrm{AN}: 4.4 \% \mathrm{DMF}$ in $1.4 \mathrm{~mol} \mathrm{~L}^{-1}$ $\mathrm{H}_{2} \mathrm{SO}_{4}$ and $\mathrm{BrO}_{3}^{-}$is prepared in aqueous acid medium.) Scan rate $=100 \mathrm{mV} \mathrm{s}^{-1}$.

$>350000$ daltons..$^{53}$ Here the yellowish color is due to bromination of the resorcinol, which can be easily separated using any organic solvent other than DMF and DMSO. The polymer has been found to be soluble in only these two solvents. In our recently published work, similar polymer was synthesized and characterized using several spectroscopic techniques and the synthesis have been performed using visible light as well for generation of radicals. The polymer isolated and separated from
BZ mixture showed similar characteristics. Further, in AN/DMF based system, minimal amplitude oscillations were observed for longer time duration and in case of Fig. 6D minimal amplitude and larger time period oscillations are observed even after $t=3000 \mathrm{~s}$. This may be due to diffusion control and extended release of some of the BZ intermediates responsible for oscillations, which are entrapped in hydrophobic environment of the polymer earlier. This behavior may be correlated

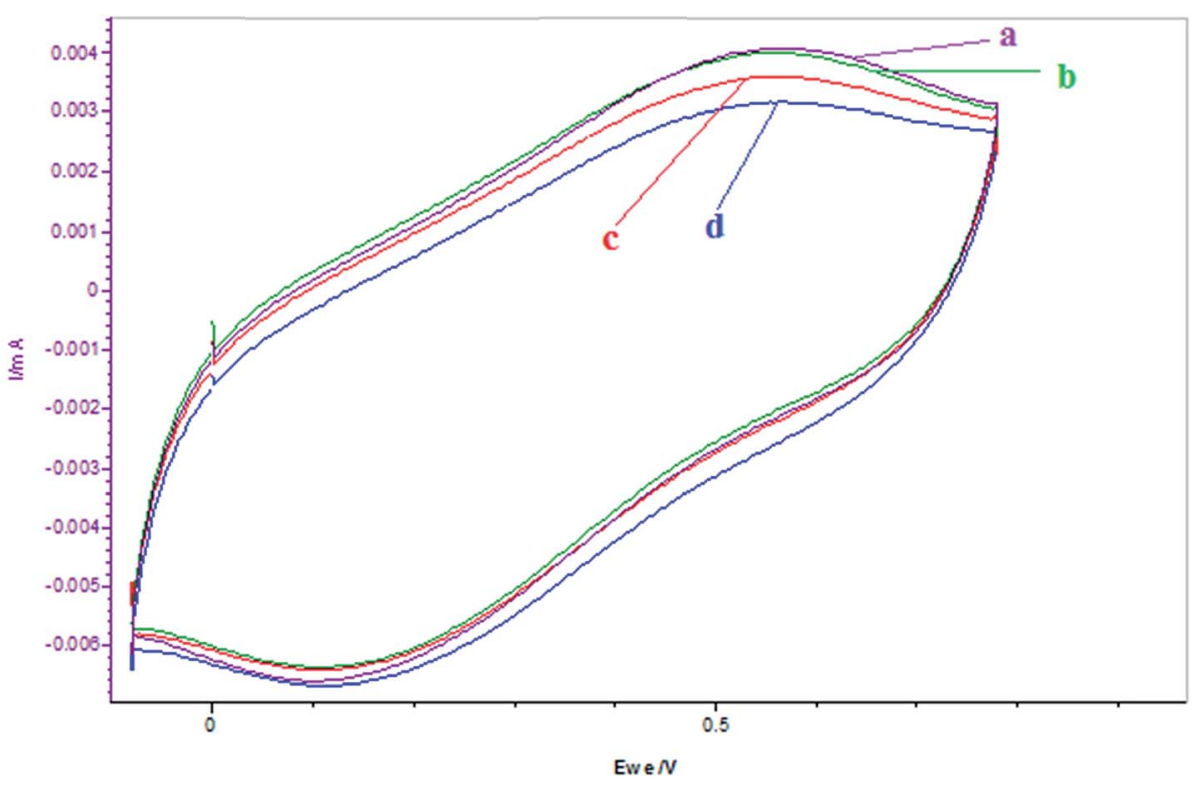

Fig. 12 Cyclic voltammograms of the reactions of $\mathrm{BrO}_{3}{ }^{-}+\alpha$-tocoferol after 10 minutes of additions of $\alpha$-tocoferol: (a) $\mathrm{BrO}_{3}{ }^{-}=5 \mathrm{~mL}^{-}$(b) $\mathrm{BrO}_{3}{ }^{-}$ $+\alpha$-tocoferol $=0.001 \mathrm{~mol} \mathrm{~L}^{-1}$, (c) $\mathrm{BrO}_{3}^{-}+\alpha$-tocoferol $=0.002 \mathrm{~mol} \mathrm{~L}^{-1}$, (d) $\mathrm{BrO}_{3}^{-}+\alpha$-tocoferol $=0.003 \mathrm{~mol} \mathrm{~L}^{-1}$. ( $\alpha$-Tocoferol is prepared in 5.6\% AN: 4.4\% DMF in $1.4 \mathrm{~mol} \mathrm{~L}^{-1} \mathrm{H}_{2} \mathrm{SO}_{4}$ and $\mathrm{BrO}_{3}{ }^{-}$is prepared in aqueous acid medium.) Scan rate $=200 \mathrm{mV} \mathrm{s}^{-1}$. 


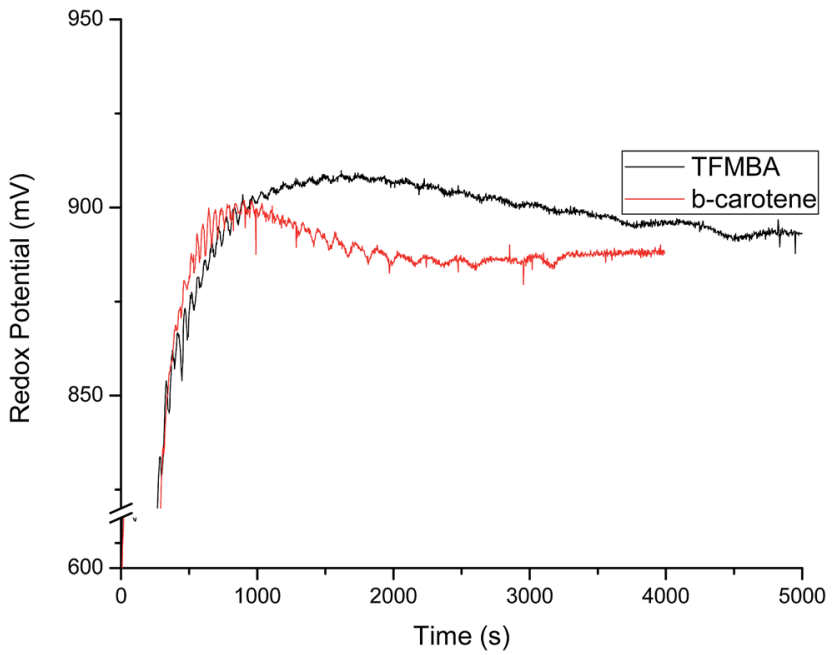

Fig. 13 Potential $(\mathrm{mV})$ versus time $(\mathrm{s})$ plots of resorcinol- $\mathrm{BrO}_{3}{ }^{-}$ $\mathrm{Mn}^{2+}-\mathrm{H}_{2} \mathrm{SO}_{4} \mathrm{BZ}$ system in 5.6\% AN: 4.4\% DMF in $1.4 \mathrm{~mol} \mathrm{~L}^{-1} \mathrm{H}_{2} \mathrm{SO}_{4}$ aqueous acid mixed media after perturbation by different antioxidants just before the addition of $\mathrm{BrO}_{3}{ }^{-}$solution. TFMBA $=0.005 \mathrm{~mol} \mathrm{~L}{ }^{-1}$ (Black), $\beta$-carotene $=0.00025 \mathrm{~mol} \mathrm{~L}^{-1}$ (Red). The concentration of $\mathrm{BZ}$ matrix is [resorcinol] $]_{0}=0.0225 \mathrm{~mol} \mathrm{~L}^{-1},\left[\mathrm{BrO}_{3}{ }^{-}\right]_{0}=0.16 \mathrm{~mol} \mathrm{~L}^{-1}$, $\left[\mathrm{Mn}^{2+}\right]_{0}=0.005 \mathrm{~mol} \mathrm{~L}^{-1}$.

with the sustained release and diffusion control of recent drugs, wherein drug release through matrix system or diffusion of drugs from reservoir coated with suitable polymers, helps the patients for longer periods of time. ${ }^{54,55}$ Similarly, the BZ intermediates and reagents also trap in the polymer matrix from where they are released in smaller concentrations, leading to small amplitude but longer time period oscillations. Further, now due to the inhomogeneity caused by the solid polymer inside the reaction mixture, appearance of some noise is also observed throughout the oscillatory regime. It is noteworthy to mention here that the resorcinol based system showed optimal oscillatory parameters only under unstirred conditions and stirring doesn't yield significant oscillatory parameters for such a study. It is to be noted that due to the bromination of the solvent, ${ }^{56}$ we used higher concentrations of bromate solutions for organic-aqueous mixed media as compared to that of aqueous acid media in our previous studies for resorcinol based BZ system. This bromination effect can be seen from continuous decrease in amplitude of oscillation (region I in Fig. 5). Further, it is observed that none of the BZ systems showed any oscillatory regime using antioxidants alone as substrates without resorcinol. Hence, it was concluded that primarily all the antioxidants may be responsible for quenching of radicals in resorcinol based chemical oscillator depending upon their structure and functionalities rather than acting as cosubstrates.

\section{$\alpha$-Tocoferol in acrylonitrile/DMF}

Fig. 8 showed the effect of [ $\alpha$-tocopherol] on the oscillatory behavior of the BZ system under investigation using potentiometry. As compared to melatonin, it showed strong quenching for concentrations $\geq 0.001$ of $\alpha$-tocopherol, with a similar appearance of minimal amplitude prolonged oscillations. The change in oscillatory parameters observed for increased $[\alpha-$ tocopherol] are similar as that of melatonin. This may be due to the fact that with the addition of $\alpha$-tocopherol, there is decrease in oxidation peak of metal ion as shown in Fig. 9. The CV plots depicted that there is continuous decrease in oxidation peak for

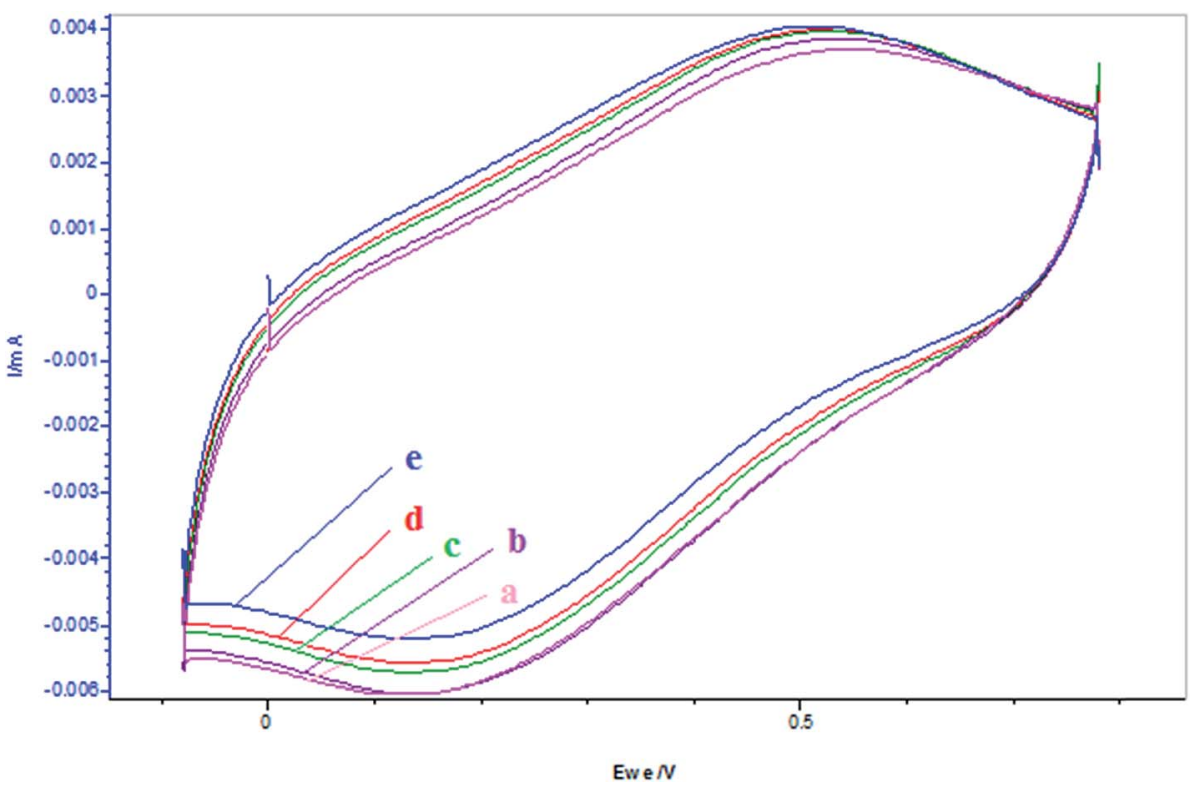

Fig. 14 Cyclic voltammograms of the reactions of $\mathrm{BrO}_{3}{ }^{-}\left(0.16 \mathrm{~mol} \mathrm{~L}^{-1}\right)+\beta$-carotene after different times of additions of $\beta$-carotene: (a) $\mathrm{BrO}_{3}{ }^{-}=$ $5 \mathrm{~mL}$, (b) $\mathrm{BrO}_{3}^{-}+\beta$-carotene $=0.001 \mathrm{~mol} \mathrm{~L}^{-1}$ after $1 \mathrm{~min}$, (c) $\mathrm{BrO}_{3}^{-}+\beta$-carotene $=0.002 \mathrm{~mol} \mathrm{~L}^{-1}$ after $10 \mathrm{~min},(\mathrm{~d}) \mathrm{BrO}_{3}^{-}+\beta$-carotene $=$ $0.003 \mathrm{~mol} \mathrm{~L}^{-1}$ after $10 \mathrm{~min},(\mathrm{e}) \mathrm{BrO}_{3}^{-}+\beta$-carotene $=0.003 \mathrm{~mol} \mathrm{~L}^{-1}$ after $10 \mathrm{~min}$. ( $\beta$-Carotene is prepared in $5.6 \% \mathrm{AN}: 4.4 \% \mathrm{DMF}$ in $1.4 \mathrm{~mol} \mathrm{~L}^{-1}$ $\mathrm{H}_{2} \mathrm{SO}_{4}$ and $\mathrm{BrO}_{3}^{-}$is prepared in aqueous acid medium.) Scan rate $=200 \mathrm{mV} \mathrm{s}^{-1}$. 
$\mathrm{Mn}^{2+}$ ion with time till whole of the antioxidant get consumed, after which there is again a steady increase (Fig. 9c and d).

Further, it is observed from the CV plots shown in Fig. 10 that the addition of $\alpha$-tocopherol to resorcinol decreased its oxidation peak, which may be attributed to its reduction by the antioxidant, which is reversed by the addition of $\mathrm{BrO}_{3}{ }^{-}$due to higher reduction potential of the later. However, there is much interaction between $\alpha$-tocopherol and $\mathrm{Mn}^{2+}$ ion observed in this media as compared to resorcinol. This can be seen from CV plots shown in Fig. 11, wherein there is larger decrease in oxidation peak for $\mathrm{Mn}^{2+}$ with the addition of $\alpha$-tocopherol. But, this decrease continues with the addition of $\mathrm{BrO}_{3}{ }^{-}$, quite opposite to the case of resorcinol. This can be attributed to the increased rate of reduction of $\mathrm{Mn}^{3+}$ by this concentration of $\alpha$ tocopherol, and the addition of $0.2 \mathrm{mmol} \mathrm{L}^{-1}$ of $\mathrm{BrO}_{3}{ }^{-}$could not oxidize it further. This can be confirmed by the $\mathrm{CV}$ plots shown in Fig. 12 for the interaction of $\mathrm{BrO}_{3}{ }^{-}$with $\alpha$-tocopherol.

With increase in $[\alpha \text {-tocopherol }]_{0}$ and time there is continuous decrease in reduction peak potential of $\mathrm{BrO}_{3}{ }^{-}$because of two reasons: one is due to extensive bromination of organic solvent, hence decreasing its concentration and the second is due to its reduction with the $\alpha$-tocopherol added.

\section{TFMBA and $\beta$-carotene in acrylonitrile/DMF}

Fig. 13 depicted the expression of oscillatory behavior with the addition of TFMBA and $\beta$-carotene at the start of reaction. The potential-time plots clearly show that there is marked quenching of oscillations for both these systems, whereas the quenching is larger for TFMBA than $\beta$-carotene. Both these antioxidants were added to the resorcinol based system with increased $\left[\mathrm{BrO}_{3}{ }^{-}\right]_{0}=0.16 \mathrm{~mol} \mathrm{~L} \mathrm{~L}^{-1}$, as there is extensive bromination of the organic solvents and $0.1 \mathrm{~mol} \mathrm{~L}^{-1}$ concentration didn't yield any oscillations after addition of antioxidants. For these systems low amplitude oscillations were observed due to quenching of radical species and also due to removal of $\mathrm{Br}_{2}$ by its involvement in bromination of organic solvent. Fig. 14 clearly depicted that addition of $\beta$-carotene to the $\mathrm{BrO}_{3}{ }^{-}$in such media, marginal increase in its anodic peak, whereas there is larger decrease in the cathodic peak with time. The decrease in cathodic peak can be due to bromination of the solvent, hence decreasing its concentration, whereas increase in anodic peak could be due to promotion of oxidation effect of the $\beta$-carotene in this solvent.

\section{Conclusions}

The use of mixed media in solubilizing the water insoluble antioxidants has been carried out for the first time in oscillatory chemical reactions. A comparative study pertaining to radical scavenging effect of different water insoluble antioxidants in two different organic-aqueous mixed media has been performed. In AN/DMF based organic-aqueous mixed medium, different amounts of inhibition of the radical polymerization took place depending upon the generation of BZ intermediates or the initial reagent concentrations. The oscillatory parameters vary significantly due to in situ polymerization and the results showed extended oscillations than the main resorcinol based BZ system. This study can be performed with a variety of biologically important hydrophobic additives in order to understand their mechanism of action with suitable reagents, thereby, can serve as prototype example for understanding the mechanisms of similar type of reactions in vivo.

\section{Acknowledgements}

The authors are thankful to Department of Science and Technology, Government of India for providing equipment grant in the form of FIST level-1 to the department. The authors also thank Head, Department of Chemistry University of Kashmir for facilitating us to undertake the work in the department.

\section{References}

1 R. J. Field and F. Schneider, Oscillating chemical reactions and nonlinear dynamics, J. Chem. Educ., 1989, 66, 195-204.

2 A. Lotka, Contribution to the theory of periodic reactions, $J$. Phys. Chem., 1910, 14, 271-274.

3 R. M. Noyes, Some models of chemical oscillators, J. Chem. Educ., 1989, 66, 190-191.

4 A. Karavayev and V. Kazakov, Chemiluminescence and freeradical stages of the Belousov-Zhabotinskii reaction, React. Kinet. Catal. Lett., 1987, 34, 15-20.

$5 \mathrm{H}$. Saigusa, Chemiluminescence detection of a phase response to an oxygen perturbation in the $\mathrm{Ru}(\mathrm{bpy})_{3}{ }^{2+}$ catalyzed Belouzov-Zhabotinskii reaction, Chem. Phys. Lett., 1989, 157, 251-256.

6 V. P. Kazakov, A. D. Karavayev and S. R. Vakhidova, Some peculiarities of chemiluminescence (CL) in BelousovZhabotinskii reactions. I. Unusual shape of CL oscillations, React. Kinet. Catal. Lett., 1991, 45, 199-205.

7 H. R. Weigt, Chemiluminescence Oscillations Driven by a Flow-Through Reactor in the $\left[\mathrm{Ru}(\mathrm{bpy})_{3}\right]^{2+}$ Catalyzed Belousov-Zhabotinskii Reaction (pages 355-357), Angew. Chem., Int. Ed. Engl., 1992, 31, 355-357.

8 A. I. Zhuravlev and V. M. Trainin, Chemiluminescent reactions in the Belousov-Zhabotinskii oscillating system, J. Biolumin. Chemilumin., 1990, 5, 227-234.

9 K. B. Yatsimirrskii, P. E. Strizhak and T. S. Ivaschenko, Potential of chaotic chemical systems in nanotrace analysis based on the Belousov-Zhabotinskii reaction $\left(\mathrm{BrO}_{3}{ }^{-}\right.$ malonic acid-ferroin). Determination of manganese(II), Talanta, 1993, 40, 1227-1232.

10 R. T. Echols, M. K. Caroll and J. F. Tyson, Flow injection study of the Belousov-Zhabotinskii reaction, Anal. Proc., 1995, 32, 3-5.

11 L. Kolar-Anic and G. Schmitz, Mechanism of the BrayLiebhafsky reaction: effect of the oxidation of iodous acid by hydrogen peroxide, J. Chem. Soc., Faraday Trans., 1992, 88, 2343-2349.

$12 \mathrm{~S}$. Anic and L. Kolar-Anic, Kinetic aspects of the BrayLiebhafsky oscillatory reaction, J. Chem. Soc., Faraday Trans. 1, 1988, 84, 3413-3421. 
13 S. Anic, L. Kolar-Anic, D. Stanisavljev, N. Begovic and D. Mitic, Dilution reinitiated oscillations in the BrayLiebhafsky system, React. Kinet. Catal. Lett., 1991, 43, 155162.

14 R. Jiménez-Prieto, M. Silva and D. Pérez-Bendito, Application of Oscillating Reaction-Based Determinations to the Analysis of Real Samples, Analyst, 1997, 122, 287-292.

15 S. Anic, D. Mitic and M. Curcija, J. Serb. Chem. Soc., 1987, 52, 575-579.

16 G. Schmitz, J. Chim. Phys. Phys.-Chim. Biol., 1987, 84, 957965.

17 A. Nagy and L. Treindl, Modifikacia Prietokoveho reaktora na sledovanie chemickych oscilacii, Chem. Listy, 1988, 82, 1097-1099.

18 M. Yoshimoto, K. Yoshikawa, Y. Mori and I. Hanazaki, Asymmetric coupling stabilizes the out-of-phase mode: experimental evidence in the Belousov-Zhabotinsky reaction, Chem. Phys. Lett., 1992, 189, 18-22.

19 I. R. Epstein, The role of flow systems in far-fromequilibrium dynamics, J. Chem. Educ., 1989, 66, 191.

20 R. Melka, B. Olsen, L. Beavers and J. Draeger, The kinetics of oscillating reactions. Laboratory experiment for physical chemistry, J. Chem. Educ., 1992, 69, 596.

21 Z. Qingyuan and C. Jie, Fenxi Shiyanshi, 1988, 7, 4.

22 M. Jiang, Y. Li, X. Zhou, Z. Zhao, H. Wang and J. Mo, Kinetic determination of hexacyanoferrates by their inhibition of an oscillating chemical reaction, Anal. Chim. Acta, 1990, 236, 411-416.

23 R. Jiménez-Prieto, M. Silva and D. Pérez-Bendito, Analyte Pulse Perturbation Technique: A Tool for Analytical Determinations in Far-from-Equilibrium Dynamic Systems, Anal. Chem., 1995, 67, 729-734.

24 R. Jiménez-Prieto, M. Silva and D. Pérez-Bendito, Determination of trace amounts of reduced glutathione by a chemical oscillating reaction, Analyst, 1996, 121, 563-566.

25 R. Jiménez-Prieto, M. Silva and D. Pérez-Bendito, Determination of gallic acid by an oscillating chemical reaction using the analyte pulse perturbation technique, Anal. Chim. Acta, 1996, 321, 53-60.

26 R. Jiménez-Prieto, M. Silva and D. Pérez-Bendito, Simultaneous determination of gallic acid and resorcinol based on an oscillating chemical reaction by the analyte pulse perturbation technique, Anal. Chim. Acta, 1996, 334, 323-330.

27 M. Orbán, Oscillations and bistability in the copper(II)catalyzed reaction between hydrogen peroxide and potassium thiocyanate, J. Am. Chem. Soc., 1986, 108, 68936898.

28 M. Orbán, Cu(II)-catalyzed oscillatory chemical reactions, React. Kinet. Catal. Lett., 1990, 42, 343-353.

29 K. Zhang, W. H. Ma, R. X. Cai, Z. X. Lin and N. Q. Gan, Determination of riboflavin by the perturbation of active oxygen on a chemical oscillating reaction, Anal. Chim. Acta, 2000, 413, 115-123.

30 J. Z. Gao, H. Yang, X. Liu, J. Ren, X. Lu, J. Hou and J. Kang, Kinetic determination of ascorbic acid by the BZ oscillating chemical system, Talanta, 2001, 55, 99-107.
31 J. Z. Gao, H. Yang, X. Liu, J. Ren, Q. Li and J. Kang, Determination of glutamic acid by an oscillating chemical reaction using the analyte pulse perturbation technique, Talanta, 2002, 57, 105-114.

32 R. J. Prieto, M. Silva and D. P. Bendito, Application of Oscillating Reaction-Based Determinations to the Analysis of Real Samples, Analyst, 1997, 122, 287-292.

33 J. Z. Gao, X. X. Wei and W. Yang, Determination of 1naphthylamine by using oscillating chemical reaction, $J$. Hazard. Mater., 2007, 144, 67-72.

34 P. E. Strizhak, O. Z. Didenko and T. S. Ivashchenko, Determination of traces of thallium using the transient chaotic regime in the Belousov-Zhabotinskii oscillating chemical reaction, Anal. Chim. Acta, 2001, 428, 15-21.

35 N. D. Pejic, et al., Kinetic determination of morphine by means of Bray-Liebhafsky oscillatory reaction system using analyte pulse perturbation technique, Anal. Chim. Acta, 2007, 582, 367-374.

$36 \mathrm{~W}$. Yang, et al., Determination of alpha-naphthol by an oscillating chemical reaction using the analyte pulse perturbation technique, Anal. Chim. Acta, 2005, 554, 218223.

37 H. Gang, L. Chen, J. Zheng, P. Chen, W. Wang, J. Song, L. Qiu, J. Song and L. Hu, Determination of Alizarin Red S using a novel B-Z oscillation system catalyzed by a tetraazamacrocyclic complex, Cent. Eur. J. Chem., 2009, $7(3), 291-297$.

38 K. B. Yatsimirskii, L. P. Tikhonova and L. N. Zakrevskaya, New oscillating chemical reactions involving copper and nickel tetraazamacrocyclic complexes, React. Kinet. Catal. Lett., 1982, 21, 381-386.

$39 \mathrm{~L} . \mathrm{Hu}, \mathrm{G} . \mathrm{Hu}$ and $\mathrm{H} . \mathrm{H} . \mathrm{Xu}$, Kinetic determination of $\mathrm{Ag}^{+}$ using a novel Belousov-Zhabotinskii oscillating system, $J$. Anal. Chem., 2006, 61, 1021-1025.

$40 \mathrm{G}$. $\mathrm{Hu}, \mathrm{L}$. $\mathrm{Hu}$ and $\mathrm{S}$. S. Ni, Oscillatory reactions in the lactic acid/acidic bromate system with a tetraazamacrocyclic nickel(II) complex as catalyst, React. Kinet. Catal. Lett., 2006, 88, 349-355.

41 G. Hu and Z. D. Zhang, A New Chemical Oscillator With a Macrocyclic Copper(II) Complex as Catalyst and Lactic Acid as the Substrate, Chem. Lett., 2006, 35, 1154-1155.

42 J. D. Xu and S. S. Ni, Oscillating reactions involving a nickel complex with a 13-membered tetraaza macrocyclic ligand in acidic bromate medium, Inorg. Chem., 1986, 25, 1264-1268.

43 G. Hu, L. Hu, Z. Q. Xu, F. X. Xie and S. S. Ni, Period of Homogeneous Oscillations in the B-Z System Involving a Tetraazamacrocyclic Complex, Asian J. Chem., 2004, 16, 1063-1068.

44 G. Hu, Z. D. Zhang, L. Hu and J. M. Song, A New Oscillating Reaction of the Belousov-Zhabotinskii-Type With a Macrocyclic Copper(II) Complex as Catalyst, Transition Met. Chem., 2005, 30, 856-860.

45 G. Hu, P. Chen, W. Wang, L. Hu, J. Song, L. Qiu and J. Song, Kinetic determination of pyrogallol by a novel oscillating chemical reaction catalyzed by a tetraazamacrocyclic complex, Electrochim. Acta, 2007, 52, 7996-8002. 
46 N. B. Ganaie and G. M. Peerzada, Catalyst, Co-ion and the media effect on the oscillatory behavior of resorcinol in the BZ reaction, J. Braz. Chem. Soc., 2009, 20, 1262-1267.

47 N. B. Ganaie and G. M. Peerzada, Effect of initial reagent concentrations on the oscillatory behavior of the BZ reaction in a batch reactor, Int. J. Chem. Kinet., 2009, 41, 650-657.

48 N. B. Ganaie, G. M. Peerzada and I. A. Shah, Effect of different counter-ions of the manganese salt as catalyst on the kinetics of resorcinol based Belousov-Zhabotinsky, Int. J. Chem. Kinet., 2013, 45, 343-353.

49 G. Bellucci, R. Bianchini and C. Chiappe, Bromination of alkenes in acetonitrile: a rate and product study, J. Org. Chem., 1991, 56, 3067-3073.

50 R. J. Field, E. Koros and R. M. Noyes, Oscillations in chemical systems. II. Thorough analysis of temporal oscillation in the bromate-cerium-malonic acid system, $J$. Am. Chem. Soc., 1972, 94, 8649-8664.

51 M. Orban, E. Koros and R. M. Noyes, Chemical oscillations during the uncatalyzed reaction of aromatic compounds with bromate. 2. A plausible skeleton mechanism, J. Phys. Chem., 1979, 83, 3056-3057.

52 S. Bohmdorfer, A. Patel, A. Hofinger, T. Netscher, L. Gille and T. Rosenau, Bromination of Tocopherols: Oxidative Halogenations and Rearrangements, Eur. J. Org. Chem., 2011, 3036-3049, DOI: 10.1002/ejoc.201100153.

53 N. B. Ganaie, G. M. Peerzada and U. Gull, In vitro Synthesis of Nearly Ultra High Molecular Weight (NUHMW) Polymers Using Solvent-Water Suspension Method, Colloid Polym. Sci., 2017, 295, 89-97.

54 M. P. Ratnaparkhi and J. P. Gupta, Sustained Release Oral Drug Delivery System - An Overview, Int. J. Pharma Res. Rev., 2013, 2, 11-21.

55 M. Jamini and A. Kothari, Sustained Release Matrix Type Drug Delivery System: A Review, J. Drug Delivery Ther., 2012, 2, 142-148.

56 P. V. Lalitha and R. Ramaswamy, Structure reactivity correlation in bromate oscillatory systems in aqueousacetonitrile mixed medium, React. Kinet. Catal. Lett., 1993, 51, 431-442. 